\title{
Comparison of the Chemical Composition and Antimicrobial Activity of Thymus serpyllum Essential Oils
}

\author{
Aneta WESOŁOWSKA ${ }^{1 *}$, Monika GRZESZCZUK² ${ }^{2}$ Dorota JADCZAK², \\ Paweł NAWROTEK ${ }^{3}$, Magdalena STRUK ${ }^{3}$ \\ ${ }^{1}$ West Pomeranian University of Technology Szczecin, Faculty of Chemical Engineering, Institute of Chemistry and Environmental Protection, \\ Aleja Piastów42, 71-065 Szczecin, Poland; anetaw@zut.edu.pl( ${ }^{*}$ correspondingauthor) \\ ${ }^{2}$ West Pomeranian University of Technology Szczecin, Faculty of Environmental Management and Agriculture, Department of Horticulture, \\ PapieżaPawtaVINo 1,71-459Szczecin,Poland;Monika.Grzeszczuk@zut.edu.pl;Dorota.Jadczak@zut.edu.pl \\ ${ }^{3}$ West Pomeranian University of Technology Szczecin, Faculty of Biotechnology and Animal Husbandry, Department of Immunology, Microbiology and \\ PhysiologicalChemistry, Aleja Piastów45, 70-311Szczecin,Poland;pawel.nawrotek@zut.edu.pl;Magdalena.Struk@zut.edu.pl
}

\begin{abstract}
The chemical composition of the essential oils obtained by hydrodistillation from the aerial parts of Thymus serpyllum and Thymus serpyllum 'Aureus' has been investigated by gas chromatography-mass spectrometry (GC-MS). Forty-seven compounds (99.67\% of the total oil) were identified in the essential oil of T. serpyllum. The main components found in the oil were carvacrol (37.49\%), $\gamma$-terpinene (10.79\%), $\beta$ caryophyllene (6.51\%), p-cymene (6.06\%), (E)- $\beta$-ocimene (4.63\%) and $\beta$-bisabolene (4.51\%). Similarly, carvacrol (44.93\%), $\gamma$-terpinene (10.08\%), p-cymene (7.39\%) and $\beta$-caryophyllene (6.77\%) dominated in the oil of T. serpyllum 'Aureus'. A total of forty three compounds were identified in this oil, representing $99.49 \%$ of the total oil content. On the basis of the obtained data it was proved that the content of 1-octen-3-ol, eucalyptol, (Z)- $\beta$-ocimene, (E)- $\beta$-ocimene, $\gamma$-terpinene, carvacrol methyl ether, germacrene $\mathrm{D}$ and $\beta$-bisabolene was significantly higher for $T$. serpyllum while T. serpyllum 'Aureus' was characterized by a significantly higher content of 3-octanone, 3-octanol, p-cymene, borneol and carvacrol. The isolated essential oils were evaluated for their antimicrobial activity against nine reference strains (Escherichia coli, Staphylococcus aureus, Staphylococcus epidermidis, Streptococcus agalactiae, Enterococcus faecalis, Bacillus cereus, Micrococcus luteus, Proteus vulgaris and Candida albicans) by the microdilution technique. Based on this test, the minimum inhibitory concentrations (MIC) of essential oil were calculated. The volatile oil obtained from $T$. serpyllum showed the highest antimicrobial activity relative to the strain of $E$. coli $(\mathrm{MIC}=0.025 \mu \mathrm{L} / \mathrm{mL})$ and to the yeast $C$. albicans ( $\mathrm{MIC}=0.05 \mu \mathrm{L} / \mathrm{mL}$ ). Similarly, a significant antimicrobial activity exhibited T. serpyllum 'Aureus' essential oil, although the MIC values obtained in that case for $E$. coli and $C$. albicans strains were twice as high and were respectively $0.05 \mu \mathrm{L} / \mathrm{mL}$ and $0.1 \mu \mathrm{L} / \mathrm{mL}$.
\end{abstract}

Keywords: antimicrobial activity, essential oil composition, hydrodistillation, wild thyme

\section{Introduction}

Thymus serpyllum L. (wild thyme, mother of thyme) belongs to the genus Thymus, which comprises about 350 species worldwide (Maksimovic et al., 2008). The aerial parts of Thymus possess antimicrobial (Ismaili et al., 2002), antioxidant (Jukic and Milos, 2005), anti-inflammatory (Broucke and Lemli, 1983), antiviral and expectorant (Nabavi et al., 2015) activities. These valuable properties are attributed with the presence of thymol, carvacrol, p-cymene and $\gamma$-terpinene in the essential oil (Dorman and Deans, 2000; Rasooli and Mirmostafa, 2002).

Thymus oils and extracts have found wide applications in cosmetic and perfume industry as well as flavourings and preservative agents for different food products (Guseinov et al.,
1987). Due to their antiseptic, antispasmodic and antimicrobial properties, they are also used for medicinal purposes (Jirovetz et al., 2007).

In traditional medicine, the flowering parts and leaves of Thymus species plants are mainly used as herbal tea, flavouring agents (condiment and spice), for treating colds, coughs, sore throat and indigestion (Zargari, 1990; Morales 2002; Amin, 2005).

Wild thyme is well-known for its cough-suppressant, antiseptic and spasmolytic properties (Zarzuelo and Crespo, 2002). Especially, a strong decoction, sweetened with honey is recommended for easing spasms of whooping cough (Aziz and Rehman, 2008). The plant can be applied for preparation of herbal tea, herbal baths and herbal pillows (Zarzuelo and Crespo, 2002). 
T. serpyllum is also an important source of substances with antioxidant, antimicrobial and antitumor properties (Jaric et al., 2015). Recent studies have shown that Serpylli aetheroleum strongly act on fungi and bacteria (Farrukh et al., 2012; SokolicMihalak et al., 2012; Nikolic et al., 2014). The oil is used medicinally as well as in the manufacturing of toothpastes, mouthwashes and gargles (Ahmad et al., 2006). According to Aziz and Rehman (2008), it can relieve rheumatism and may be used in hair loss treatments.

The high quality of essential oil is one of the main requirements of pharmaceutical and food industry. The essential oils derived from various Thymus species may differ in chemical composition and biological properties. Their market value may also be different.

Our previous studies concerned the influence of distillation time and distillation apparatus on the composition and quality of wild thyme oil (Wesołowska et al., 2012; Wesołowska et al., 2014).

The medicinal importance and biological activity of $T$. serpyllum volatile oil prompted us to investigate its cultivar 'Aureus'. The present study aimed to compare the chemical composition and antimicrobial activity of the oils extracted from T. serpyllum and T. serpyllum 'Aureus'. To the best of our knowledge, there are no scientific reports concerning this topic. Similarly, there is lack of publications on the composition and biological activity of oil obtained from T. serpyllum 'Aureus'.

\section{Materials and Methods}

\section{Plantmaterial}

The studied biological material used in the current research consisted of wild thyme (Thymus serpyllum L.) and wild thyme 'Aureus' (Thymus serpyllum 'Aureus') from the Lamiaceae family. All the plants were grown in experimental plots with an area of 1.44 $\mathrm{m}^{2}$, in four replications at the Horticultural Experimental Station near Szczecin (North-Western Poland), which belongs to the West Pomeranian University of TechnologySzczecin.

The seedlings, obtained from older plants, after rooting in horticultural substrate, were planted into the open field in the second half of May 2012, with spacing of $20 \times 20 \mathrm{~cm}$. For laboratory analyses, an herb from two-year-old plants was harvested at the flowering stage (harvest date: July 8, 2014). The field was prepared according to agrotechnique proper for thyme cultivation. Mineral fertilization was quantified according to the results of the chemical analysis of the soil samples and supplemented to those recommended for thyme level. In the first year of the experiment only nitrogen $\left(60 \mathrm{~kg} \mathrm{~N} \mathrm{ha}^{-1}\right)$ and potassium $\left(60 \mathrm{~kg} \mathrm{~K}_{2} \mathrm{O} \mathrm{ha} \mathrm{h}^{-1}\right)$ fertilization was applied, while in the second year - potassium $(60 \mathrm{~kg}$ $\left.\mathrm{K}_{2} \mathrm{Oha}^{-1}\right)$ and phosphorous $\left(60 \mathrm{kgP}_{2} \mathrm{O}_{5}\right.$ ha $\left.^{-1}\right)$ fertilization.

The experiment was performed on sandy clay soil, which is characterized by low water-holding capacity. During the growing season manual weeding and irrigation were performed.

After the harvest, plant material was dried in a shady and well ventilated place at room temperature (drying room). Dry herb was cut into small pieces and stored (in paper bags in a dry and cool place) until chemical analyses were performed.

\section{Essential oil extraction}

Twenty grams of the whole dried aerial parts of T. serpyllum and T. serpyllum 'Aureus' (separately) in a $1000 \mathrm{~mL}$ round- bottomed flask along with $500 \mathrm{~mL}$ distilled water was subjected to hydrodistillation for 2 hours using Clevenger apparatus according to the method recommended by European Pharmacopoeia (2010). The obtained essential oils were separated from water, then dried over anhydrous sodium sulphate, filtered and stored in dark sealed vial at low temperature $\left(4^{\circ} \mathrm{C}\right)$ prior to GC-MS analysis.

Gas Chromatography/Mass Spectrometry (GC/MS) analyses of essential oils

The qualitative analysis was conducted using HP 6890 gas chromatograph coupled with HP 5973 Mass Selective Detector operating at $70 \mathrm{eV}$ mode. The essential oil samples $(30 \mathrm{mg})$ were dissolved in dichloromethane $(1.5 \mathrm{~mL})$ and $2 \mu \mathrm{L}$ of each solution were injected in a split mode at a ratio of 5:1. Compounds were separated on $30 \mathrm{~m}$ long capillary column (HP-5MS), $0.25 \mathrm{~mm}$ in diameter and with $0.25 \mu \mathrm{m}$ thick stationary phase film $((5 \%$ phenyl)-methylpolysiloxane).

The flow rate of helium through the column was kept at 1.2 $\mathrm{mL} \min ^{-1}$. The initial temperature of the column was $40^{\circ} \mathrm{C}$ for 5 minutes, then increased to $60^{\circ} \mathrm{C}$ at a rate of $30^{\circ} \mathrm{C} \mathrm{min}{ }^{-1}$, next to $230^{\circ} \mathrm{C}$ at a rate of $6^{\circ} \mathrm{C} \mathrm{min}^{-1}$ (kept constant for $10 \mathrm{~min}$ ), and then increased to a final temperature of $280^{\circ} \mathrm{C}$ at a rate of $30^{\circ} \mathrm{C}$ $\mathrm{min}^{-1}$. The oven was held at this temperature for 5 minutes. The injector and the transfer line were kept at $280^{\circ} \mathrm{C}$. The ion source temperature was $230^{\circ} \mathrm{C}$. The solvent delay was $4 \mathrm{~min}$. The scan range of the MSD was set from 40 to $550 \mathrm{~m} / \mathrm{z}$. The total running time for a sample was about 51 minutes.

The relative percentage of the essential oil constituents was evaluated from the total peak area (TIC) by apparatus software.

Essential oil constituents were identified by comparison of their retention indices (relative to n-alkanes $\mathrm{C}_{7}-\mathrm{C}_{40}$ on HP-5MS column) with those reported in NIST Chemistry WebBook (http://webbook.nist.gov/chemistry) and the literature (Adams, 2007).

Further identification was made by comparison of their mass spectra with those stored in the Wiley NBS75K.L and NIST/EPA/NIH (2002 version) mass spectral libraries using different search engines (PBM, Nist02) or with mass spectra of authentic compounds available in our laboratory (thymol, carvacrol and p-cymene), purchased from Fluka and SigmaAldrich.

\section{Antimicrobial activity}

Nine reference strains were tested: six Gram-positive bacteria Staphylococcus aureus (FRI 913), Staphylococcus epidermidis (ATCC 49461), Streptococcus agalactiae (ATCC 12386), Enterococcus faecalis (ATCC 29212), Bacillus cereus (ATCC 14579) and Micrococcus luteus (ATCC 10240); two Gramnegative bacteria Escherichia coli (MG1655) and Proteus vulgaris (ATCC 6380) and yeast Candida albicans (ATCC 10231).

The bacteria species were maintained in Brain Heart Infusion Agar (BHIA, Emapol, Poland) and C. albicans was maintained on Sabouraud Dextrose Agar (SDA, Emapol, Poland).

$$
\begin{aligned}
& \text { Antimicrobialscreening } \\
& \text { Minimum inhibitory (MIC) and minimum } \\
& \text { bactericidal/fungicidal (MBC/MFC) concentrations were } \\
& \text { determined by microdilution method in } 96 \text {-well microtitre } \\
& \text { plates described by Wiegand et al. (2008) as well as Levic et al. }
\end{aligned}
$$


434

(2011) with slight modifications (in case of yeast, the time of SDA plates incubation at $37^{\circ} \mathrm{C}$ was prolonged to $48 \mathrm{~h}$ ). The bacterial/fungal inoculates were prepared using fresh overnight cultures and suspensions was adjusted to $0.5 \mathrm{McF}$ arland standard turbidity using turbidimeter (Biosan). Essential oils were diluted in propylene-glycol (2-(2-hydroxypropoxy)-1propanol) to the test concentration ranging from 500 to 2 $\mu \mathrm{L} / \mathrm{mL}$. The optical density of tested microorganisms cells (OD, $\lambda=600 \mathrm{~nm}$ ) under exposure to tested oils were used to quantify of results. The optical density of tested microorganisms cells was measured at the wavelength of $600 \mathrm{~nm}$ in 96-well microtitre plates with $200 \mu \mathrm{L}$ of each sample using Infinite 200 PRO NanoQuant microplate reader (Tecan, Männedorf, Switzerland).

All tests were performed in Mueller Hinton Broth (MHB, Emapol, Poland), in a volume of $200 \mu \mathrm{L}$. The aliquots $20 \mu \mathrm{L}$ bacteria (or yeast) suspensions and $20 \mu \mathrm{L}$ essential oil in geometric dilutions (ranging from $500 \mu \mathrm{L}$ to $0.125 \mu \mathrm{L}$ ) were added into each well of 96-well microtitre plate. Then, aliquots of $160 \mu \mathrm{L}$ of $\mathrm{MHB}$ were added. The final essential oils concentrations were 50 to $0.0125 \mu \mathrm{L} / \mathrm{mL}$. Simultaneously sterility control (MHB + tested oils) and control of toxicity of propylene glycol $(\mathrm{MHB}+$ tested microorganisms + propylene glycol) were performed. As the controls of all tests, the same tested microorganisms, incubated under the same conditions but without exposure to tested oils were used.

The microplates were incubated for $24 \mathrm{~h}$ at $37^{\circ} \mathrm{C}$ for bacteria and $48 \mathrm{~h}$ at $37^{\circ} \mathrm{C}$ for yeast. The MIC was defined as the lowest concentration of essential oil at which microorganism shows no visible growth. Then, the $5 \mu \mathrm{L}$ solution from each well was transferred to BHIA plates (Emapol) and incubated for $24 \mathrm{~h}$ at $37^{\circ} \mathrm{C}$ for bacteria. For yeast SDA plates (Emapol) were used and incubated for $48 \mathrm{~h}$ at $37^{\circ} \mathrm{C}$. The lowest concentration of the essential oil at which $99.5 \%$ inoculated microorganisms were killed was defined as MBC for bacteria and MFC for yeast. All tests with the controls were repeated three times.

\section{Statistical analysis}

In order to observe the differences in the composition of $T$. serpyllum and T. serpyllum 'Aureus' oils, seventeen constituents of the content greater than $1 \%$ of the oil were selected for statistical analysis. An analysis of variance was performed using AWAR software made by Department of Applied Informatics, Institute of Soil Science and Plant Cultivation in Puławy. The means were separated by the Tukey's test at $\mathrm{p}=0.05$.

The data gathered in Table 4 are presented as the means \pm standard deviations (mean \pm SD) calculated for the three repetitions of the experiment using Statistica 9.0 (StatSoft, Poland).

\section{Results}

\section{Chemical composition of essential oils}

The essential oils isolated by hydrodistillation from the aerial parts of T. serpyllum and T. serpyllum 'Aureus' were found to be yellow liquids and were obtained with a yield of $1.50 \%(\mathrm{v} / \mathrm{w})$ and $1.45 \%$ (v/w), based on the dry weight of plant material. The present results are in conformity with the European Pharmacopoeia (2010) standard for T. serpyllum herb (a yield of at least $0.3 \%$ ).

According to literature data, the content of essential oil in $T$. serpyllum is variable and depends mainly on the origin of the plants,
Table 1. Relative percentage composition of wild thyme (Thymus serpyllum $\mathrm{L}$.) essential oils

\begin{tabular}{|c|c|c|c|}
\hline Compounds & RI & T.serpyllum & $\begin{array}{l}\text { T. serpyllum } \\
\text { 'Aureus' }\end{array}$ \\
\hline$\alpha$-Thujene & 927 & 1.59 & 1.43 \\
\hline$\alpha$-Pinene & 933 & 0.73 & 0.98 \\
\hline Camphene & 948 & 0.07 & 0.60 \\
\hline Sabinene & 973 & 0.11 & - \\
\hline$\beta$-Pinene & 976 & 0.47 & 0.31 \\
\hline 1-Octen-3-ol & 980 & 2.15 & 0.38 \\
\hline 3-Octanone & 987 & 0.18 & 6.19 \\
\hline$\beta$-Myrcene & 991 & 1.75 & 1.79 \\
\hline 3-Octanol & 996 & 0.28 & 1.39 \\
\hline$\alpha$-Phellandrene & 1004 & 0.33 & 0.49 \\
\hline$\delta$-3-Carene & 1010 & 0.13 & 0.24 \\
\hline$\alpha$-Terpinene & 1016 & 2.09 & 2.15 \\
\hline p-Cymene & 1025 & 6.06 & 7.39 \\
\hline$\beta$-Phellandrene & 1029 & 0.24 & 0.69 \\
\hline Eucalyptol & 1031 & 3.71 & 0.90 \\
\hline (Z)- $\beta$-Ocimene & 1038 & 1.14 & 0.25 \\
\hline (E)- $\beta$-Ocimene & 1049 & 4.63 & 0.12 \\
\hline$\gamma$-Terpinene & 1061 & 10.79 & 10.08 \\
\hline cis-Sabinene hydrate & 1068 & 0.95 & 0.72 \\
\hline$\alpha$-Terpinolene & 1089 & 0.16 & 0.18 \\
\hline Linalool & 1101 & 0.54 & 0.90 \\
\hline Borneol & 1169 & 0.18 & 2.10 \\
\hline Terpinen-4-ol & 1181 & 0.56 & 0.67 \\
\hline$\alpha$-Terpineol & 1196 & 0.56 & 0.11 \\
\hline Thymol methyl ether & 1236 & 0.06 & - \\
\hline Carvacrol methyl ether & 1245 & 4.40 & 2.58 \\
\hline Thymol & 1293 & 0.22 & 0.27 \\
\hline Carvacrol & 1311 & 37.49 & 44.93 \\
\hline p-Thymol & 1338 & 0.24 & 0.29 \\
\hline$\alpha$-Copaene & 1380 & 0.09 & 0.11 \\
\hline$\beta$-Bourbonene & 1390 & 0.16 & 0.31 \\
\hline$\beta$-Caryophyllene & 1427 & 6.51 & 6.77 \\
\hline$\beta$-Cubebene & 1435 & 0.17 & 0.17 \\
\hline Aromadendrene & 1445 & - & 0.05 \\
\hline$\alpha$-Bergamotene & 1439 & 0.07 & - \\
\hline$\alpha$-Caryophyllene & 1460 & 0.39 & 0.34 \\
\hline Alloaromadendrene & 1468 & - & 0.13 \\
\hline$\gamma$-Muurolene & 1482 & 0.41 & 0.55 \\
\hline Germacrene D & 1488 & 1.33 & 0.31 \\
\hline Bicyclogermacrene & 1501 & 0.19 & 0.32 \\
\hline$\alpha$-Muurolene & 1505 & 0.12 & 0.20 \\
\hline$\beta$-Bisabolene & 1513 & 4.51 & 0.07 \\
\hline$\gamma$-Cadinene & 1520 & 0.63 & 0.38 \\
\hline$\delta$-Cadinene & 1528 & 0.71 & 0.82 \\
\hline Caryophyllene oxide & 1592 & 0.83 & 0.71 \\
\hline$\tau$-Cadinol & 1652 & - & 0.12 \\
\hline Octadecanal & 2042 & 0.28 & - \\
\hline 2-Methyleicosane & 2055 & 0.45 & - \\
\hline 3-Methyleicosane & 2071 & 0.34 & - \\
\hline Nonadecanal & 2119 & 0.67 & - \\
\hline Total identified & & 99.67 & 99.49 \\
\hline
\end{tabular}

but usually is between 0.1 and $1 \%$ (Raal et al., 2004). In Poland, the amounts of essential oil among wild growing populations vary from 0.21 to $0.60 \%$ (Pióro-Jabrucka and Osińska, 2003). However, plants grown in different regions of Jordan contain from 2.5 to $5.6 \%$ of oil (Abu-Darwish et al., 2009).

The relative percentage composition of essential oils and retention indices calculated for individual components of the oils are given in Table 1. All the constituents are listed in order of their elution from HP-5MS column. 
Table 2. Statistical analysis of the content of main constituents of investigated essential oils

\begin{tabular}{|c|c|c|c|}
\hline \multirow{2}{*}{ Essential oil constituent (factor I) } & \multicolumn{2}{|c|}{ Cultivar (factor $I I)$} & \multirow{2}{*}{ Mean } \\
\hline & T. serpyllum & T. serpyllum 'Aureus' & \\
\hline$\alpha$-Thujene & $1.59 \pm 0.03$ & $1.43 \pm 0.03$ & 1.51 \\
\hline 1-Octen-3-ol & $2.15 \pm 0.20$ & $0.38 \pm 0.03$ & 1.27 \\
\hline 3-Octanone & $0.18 \pm 0.01$ & $6.19 \pm 0.03$ & 3.19 \\
\hline$\beta$-Myrcene & $1.75 \pm 0.04$ & $1.79 \pm 0.01$ & 1.77 \\
\hline 3-Octanol & $0.28 \pm 0.02$ & $1.39 \pm 0.02$ & 0.84 \\
\hline$\alpha$-Terpinene & $2.09 \pm 0.03$ & $2.15 \pm 0.05$ & 2.12 \\
\hline p-Cymene & $6.06 \pm 0.04$ & $7.39 \pm 0.19$ & 6.73 \\
\hline Eucalyptol & $3.71 \pm 0.16$ & $0.90 \pm 0.02$ & 2.31 \\
\hline (Z)- $\beta$-Ocimene & $1.14 \pm 0.01$ & $0.25 \pm 0.00$ & 0.70 \\
\hline (E)- $\beta$-Ocimene & $4.63 \pm 0.03$ & $0.12 \pm 0.02$ & 2.38 \\
\hline$\gamma$-Terpinene & $10.79 \pm 0.06$ & $10.08 \pm 0.01$ & 10.44 \\
\hline Borneol & $0.18 \pm 0.04$ & $2.10 \pm 0.08$ & 1.14 \\
\hline Carvacrol methyl ether & $4.40 \pm 0.16$ & $2.58 \pm 0.09$ & 3.49 \\
\hline Carvacrol & $37.49 \pm 1.09$ & $44.93 \pm 0.58$ & 41.21 \\
\hline$\beta$-Caryophyllene & $6.51 \pm 0.18$ & $6.77 \pm 0.17$ & 6.64 \\
\hline Germacrene D & $1.33 \pm 0.14$ & $0.31 \pm 0.05$ & 0.82 \\
\hline$\beta$-Bisabolene & $4.51 \pm 0.53$ & $0.07 \pm 0.01$ & 2.29 \\
\hline Mean & 5.22 & 5.23 & 5.22 \\
\hline $\mathrm{LSD}_{\alpha=0.05}$ for factor I & 1.389 & & \\
\hline $\mathrm{LSD}_{\alpha=0.05}$ for factor II & n.s. & & \\
\hline $\mathrm{LSD}_{\alpha=0.05}$ for interaction I x II & 0.509 & & \\
\hline
\end{tabular}

Table 3. Main chemical classes of compounds identified in analysed essential oils (in \%)

\begin{tabular}{lcc}
\hline & T. serpyllum & T. serpyllum 'Aureus' \\
\hline Monoterpene hydrocarbons & 30.29 & 26.70 \\
Oxygenated monoterpenes & 6.50 & 5.40 \\
Sesquiterpene hydrocarbons & 15.29 & 10.53 \\
Oxygenated sesquiterpenes & 0.83 & 0.83 \\
Phenolic compounds & 42.41 & 48.07 \\
Total & 95.32 & 91.53 \\
\hline
\end{tabular}

Table 4. Antimicrobial activity of Thymus essential oils $(\mu \mathrm{L} / \mathrm{mL})$

\begin{tabular}{lccc}
\hline \multirow{2}{*}{ Strains } & \multicolumn{2}{c}{ T. serpyllum L. oil } & \multicolumn{2}{c}{ T. serpyllum 'Aureus' oil } \\
\cline { 2 - 4 } & MIC & MBC/MFC & MIC \\
\hline S. aureus & $0.1 \pm 0.00$ & $0.78 \pm 0.00$ & $0.1 \pm 0.00$ \\
S. epidermidis & $0.78 \pm 0.26$ & $1.56 \pm 0.00$ & $0.7 \pm \pm 0.26$ \\
S. agalactiae & $0.1 \pm 0.03$ & $0.78 \pm 0.23$ & $0.1 \pm 0.03$ \\
E. faecalis & $0.1 \pm 0.03$ & $0.78 \pm 0.45$ & $0.1 \pm 0.03$ \\
B. cereus & $0.1 \pm 0.00$ & $0.39 \pm 0.26$ & $0.2 \pm 0.11$ \\
M. luteus & $0.1 \pm 0.00$ & $1.56 \pm 0.45$ & $0.2 \pm 0.06$ \\
E. coli & $0.025 \pm 0.00$ & $0.1 \pm 0.03$ & $0.05 \pm 0.00$ \\
$P$. vulgaris & $0.1 \pm 0.08$ & $0.78 \pm 0.26$ & $0.39 \pm 0.00$ \\
\hline C. albicans & $0.05 \pm 0.00$ & $0.1 \pm 0.03$ & $0.78 \pm 0.00$ \\
\hline Values are given as mean \pm SD. MIC: minimum inhibitory concentrations. MBC: minimum bactericidal concentrations. MFC: minimum fungicidal concentrations.
\end{tabular}

A total of 47 compounds were identified in the oil of $T$. serpyllum representing $99.67 \%$ of the total oil, and 43 compounds were identified in the oil of Thymus serpyllum 'Aureus', representing 99.49\% of the total oil (Table 1).

The major constituents of $T$. serpyllum oil were carvacrol (37.49\%), $\gamma$-terpinene (10.79\%), $\beta$-caryophyllene (6.51\%), pcymene (6.06\%), (E)- $\beta$-ocimene (4.63\%) and $\beta$-bisabolene (4.51\%). Among other constituents found in significant amounts were carvacrol methyl ether (4.40\%) and eucalyptol (3.71\%). Similarly, carvacrol (44.93\%), $\gamma$-terpinene (10.08\%), p-cymene (7.39\%) and $\beta$ caryophyllene (6.77\%) were the most abundant constituents in the essential oil of $T$. serpyllum 'Aureus'. The oil contained also high amount of 3-octanone (6.19\%).
Significant differences in the chemical composition of both essential oils can clearly be observed from the results of statistical analysis presented in Table 2 .

Carvacrol was found to be the main essential oil constituent for both of the wild thyme cultivars. Its amount was on average $41.21 \%$. Lower amounts were detected as follows: $\gamma$-terpinene (on average $10.44 \%$ ) < p-cymene and $\beta$-caryophyllene (on average 6.69\%) < carvacrol methyl ether, 3-octanone, (E)- $\beta$-ocimene, eucalyptol, $\beta$ bisabolene and $\alpha$-terpinene (on average $263 \%$ ) $<\beta$-myrcene, $\alpha$ thujene, 1-octen-3-ol, borneol, 3-octanol, germacrene $D$ and (Z)- $\beta$ ocimene (on average $1.15 \%$ ).

For most of the analysed essential oil constituents there were significant differences found between their content in Thymus 
436

serpyllum L. and Thymus serphyllum 'Aureus'. The content of 1octen-3-ol, eucalyptol, (Z)- $\beta$-ocimene, (E)- $\beta$-ocimene, $\gamma$-terpinene, carvacrol methyl ether, germacrene $\mathrm{D}$ and $\beta$-bisabolene was significantly higher for T. serpyllum while T. serpyllum 'Aureus' was characterized by a significantly higher content of 3-octanone, 3octanol, p-cymene, borneol and carvacrol.

The investigated essential oils were composed mainly of three different chemical classes of compounds: phenolic compounds (42.41\% T. serpyllum; 48.07\% T. serpyllum 'Aureus'), monoterpene hydrocarbons (30.29\% T. serpyllum; 26.70\% T. serpyllum 'Aureus') and sesquiterpene hydrocarbons (15.29\% T. serpyllum; $10.53 \% T$. serpyllum 'Aureus') (Table 3). Moreover, T. serpyllum oil contained higher amount of monoterpene and sesquiterpene hydrocarbons, while T. serpyllum 'Aureus' oil was richer in phenolic compounds.

\section{Antimicrobialactivity}

The antimicrobial activity of $T$. serpyllum oils was evaluated against Gram-positive and Gram-negative bacterial strains as well as for yeast Candida albicans using the microdilution method. The obtained results are summarized in Table 4. It was demonstrated a significant, but varied for each of the analysed test strains the antimicrobial activity of essential oils. At the same time, based on conducted scientific controls, the sterility of tested essential oils was confirmed and also the toxicity of propylene glycol was excluded with respect to all of the tested microorganisms. Reported values of MIC and MBC/MFC were respectively in the case of the $T$. serpyllum L. essential oil 0.025-0.78 $\mu \mathrm{L} / \mathrm{mL}$ and $0.1-1.56 \mu \mathrm{L} / \mathrm{mL}$, whereas for the T. serpyllum 'Aureus' essential oil 0.05-0.39 $\mu \mathrm{L} / \mathrm{mL}$ and $0.1-1.56 \mu \mathrm{L} / \mathrm{mL}$.

The $T$. serpyllum L. essential oil showed the highest antimicrobial activity relative to the strain of $E$. coli $(\mathrm{MIC}=0.025$ $\mu \mathrm{L} / \mathrm{mL}$ and $\mathrm{MBC}=0.1 \mu \mathrm{L} / \mathrm{mL}$ ) and to $C$. albicans (MIC $=0.05$ $\mu \mathrm{L} / \mathrm{mL}$ and $\mathrm{MFC}=0.1 \mu \mathrm{L} / \mathrm{mL})$, however the lowest to the strain of S. epidermidis (MIC $=0.78 \mu \mathrm{L} / \mathrm{mL}$ and $\mathrm{MBC}=1.56 \mu \mathrm{L} / \mathrm{mL}$ ), and to M. luteus $(\mathrm{MBC}=1.56 \mu \mathrm{L} / \mathrm{mL})$. Similarly, a significant antimicrobial activity exhibited the T. serpyllum 'Aureus' essential oil, although the MIC values obtained in that case for $E$. coli and $C$. albicans strains were twice as high and were respectively $(0.05 \mu \mathrm{L} / \mathrm{mL}$ and 0.1 $\mu \mathrm{L} / \mathrm{mL}$ ). On the other hand, the lowest antimicrobial activity of the T. serpyllum 'Aureus' essential oil showed relative to the strain of $P$. vulgaris $(\mathrm{MIC}=0.39 \mu \mathrm{L} / \mathrm{mL}$ and $\mathrm{MBC}=0.78 \mu \mathrm{L} / \mathrm{mL}$ ), and strains of $S$. epidermidis and $E$. faecalis, for which the observed for that oil $\mathrm{MBC}$ value was as high as $1.56 \mu \mathrm{L} / \mathrm{mL}$.

\section{Discussion}

The present results are in agreement with the data provided by other authors who also showed significant antimicrobial effect after the application of $O$. vulgare, T. vulgaris, T. serpyllum, as well as T. algerientis essential oils (Lambert et al., 2001; Levic et al., 2011; Nikolic et al., 2014). Similarly to Hammer et al. (1999), the lowest values of minimum inhibitory concentrations (MIC) were shown for tested strains of $E$. coli and $C$. albicans. This may prove the particular sensitivity of these microorganisms to the essential oils. Significant antimicrobial activity of these oils is mainly connected with the destruction of the integrity and function of biological membranes of microbial cells exposed to their operation (Lambert et al., 2001). An essential role in this mechanism may be especially performed by carvacrol - an organic compound that constituted a dominant ingredient of both analysed essential oils (Tables 1 and 2). Soković et al. (2010) have proved that this compound had the greatest antimicrobial properties among all tested ingredients, including: camphor, 1,8cineole, linalool, linalyl acetate, limonene, menthol, $\alpha$ - pinene, $\beta$ pinene and thymol. The similar activity of essential oils containing large amount of carvacrol has been pointed out by other researchers (Rasooli and Mirmostafa, 2002; Abed et al. 2014). Varga et al. (2015) additionally emphasize that essential oils of Thymus species, whose one of the most important ingredients is carvacrol, show a very wide spectrum of activity both against Gram-positive and Gram-negative bacteria and against yeast. Thus, these biologically active substances may play a significant role in the prevention of serious bacterial and fungal infections as pharmaceutical formulations or natural food preservatives (Hammer et al., 1999; Lambert et al., 2001).

The biological activity of essential oils depends mainly on the chemical structure of their components and their concentrations. Generally, phenolic compounds, terpenes, aliphatic alcohols, aldehydes, ketones, acids, and flavonoids are recognized as major components with antimicrobial activity, which can be found in plants. Among them, thymol, carvacrol, pcymene and $\gamma$-terpinene are considered as the most potent (Shelef, 1983; Farag et al., 1989; Davidson, 1993; Santoyo et al., 2006). Sikkema et al. (1995) reported that these compounds act on microbial cells and cause structural and functional damage of their membranes, resulting in increased permeability.

The content of these active compounds in the essential oil of T. serpyllum varies depending on the origin of the raw material. Thymol (53.33\%), carvacrol (10.40\%) and p-cymene (8.80\%) dominated in the oil from plants collected in Pakistan (Ahmad $e t$ al., 2006). Thymol (34.61-49.53\%), $\gamma$-terpinene (8.26-9.30\%) and p-cymene (7.43-11.45\%) were the most abundant constituents of oil from Uttarakhand, India (Chauhan et al., 2011). Similarly, T. serpyllum cultivated in Kumaon region of Western Himalaya (India), contained thymol (19.40-60.10\%), $\gamma$-terpinene $(0.30-13.80 \%)$ and p-cymene $(3.50-10.40 \%)$ as major oil components (Verma et al., 2011). Moreover, thymol (46.24-74.92\%) and carvacrol (4.69-7.19\%) rich volatile oils were also obtained from plants grown in Western Nepal and North India (Thakuri et al., 2009). In Libia (Eweis et al., 2012), thymol (64.20\%) and $\beta$-phellandrene (13.50\%) accounted for the most abundant components of wild thyme oil. In Southern Italy (De Lisi et al., 2011), thymol (32.57\%), $\alpha$-terpinene $(22.83 \%)$ and $\gamma$-terpinene $(9.15 \%)$ were found as the main essential oil constituents.

In contrast, the major constituents noted in the oil from $T$. serpyllum growing wild in Estonia, were (E)-nerolidol (1.70$70.10 \%)$, caryophyllene oxide $(1.40-45.00 \%)$, $\beta$-myrcene (tr.$20.20 \%)$, $\beta$-caryophyllene (1.80-13.30\%) and germacrene D (1.70-12.50\%) (Raal et al., 2004). However, plants grown in Lithuania, contained mainly (E)-B-ocimene (0.70-34.80\%), 1,8cineole (0,70-30.30\%), borneol (0.10-27.10\%), (Z)- $\beta$-ocimene $(0.10-20.00 \%)$ and $\beta$-myrcene $(0.10-16.90 \%)$ (Loziene and Venskutonis, 2006). Similarly, wild populations of T. serpyllum in Central Poland, were characterized by the presence of camphene (8.07-13.91\%), $\beta$-myrcene (6.53-17.97\%), 1,8-cineole (1.41-11.64\%), $\beta$-caryophyllene (1.06-9.02\%) and borneol (0.15$16.91 \%$ ) in the essential oils (Osińska et al., 2002).

Interestingly, linalool (40.35-88.18\%), trans-geraniol (0.49$30.01 \%)$, geraniol acetate $(0.56-7.04 \%)$ and nerol acetate $(0.22-$ $3.11 \%)$ dominated in the essential oils of wild thyme collected 
from the territory of European North-East Russia and Ural (Alekseeva and Gruzdev, 2012). Uncharacteristic compounds, such as: 2,4,6-trimethylanisol (73.41\%), 3,5-dimethyl benzoic acid (5.38\%) and $\beta$-bisabolene (3.67\%), were present in the essential oil obtained from plants growing in Turkey (Topal et al., 2008).

In this study, volatile oils isolated from T. serpyllum and $T$. serpyllum 'Aureus' were composed mainly from carvacrol (37.49 and $44.93 \%), \gamma$-terpinene (10.08 and $10.79 \%)$, p-cymene (6.06 and $7.39 \%)$ and $\beta$-caryophyllene (6.51 and 6.77\%). The content of thymol in the all analysed oil samples was lower as compared to the results obtained by researchers from Pakistan (Ahmad et al., 2006), India (Chauhan et al., 2011), Libia (Eweis et al., 2012) and Southern Italy (De Lisi et al., 2011). However, the amount of carvacrol was almost identical to that reported by Oszagyan et al. (1996) for wild thyme growing in Hungary (39.50-45.90\%).

Comparing the content of active ingredients in both essential oils, it appears that $T$. serpullum 'Aureus' oil should be more effective against tested microbial strains. Surprisingly, slightly higher activity against $E$. coli and $C$. albicans was noted for $T$. serpyllum oil. Probably less abundant constituents of the oil are also responsible for the antimicrobial activity. They may be involved in some type of synergism with the other active compounds.

\section{Conclusion}

In all two Thymus essential oils, carvacrol, $\gamma$-terpinene, $\mathrm{p}$-cymene and $\beta$-caryophyllene were identified as the major oil constituents. The investigated oils were the most active against Escherichia coli and yeast Candida albicans, and less potent against Staphylococcus epidermidis, Enterococcus faecalis, Micrococcus luteus and Proteus vulgaris. The current study suggest the potential use of $T$. serpyllum and $T$. serpyllum 'Aureus' oils as antimicrobials for food preservation as well as in pharmaceutical formulations for prevention of bacterial and fungal infections.

\section{References}

Abed NEl, Kaabi B, Smaali MI, Chabbouh M, Habibi K, Mejri M, Marzouki MN, Ahmed SBH (2014). Chemical composition, antioxidant and antimicrobial activities of Thymus capitata essential oil with its preservative effect against Listeria monocytogenes inoculated in minced beef meat. Evidence-Based Complementary and Alternative Medicine doi:10.1155/2014/152487.

Abu-Darwish MS, Abu Dieyeh ZH, Mufeed B, Al-Tawaha ARM, Aldalain SYA (2009).Trace element contents and essential oil yields from wild thyme plant (Thymus serpyllum L.) grown at different natural variable environments, Jordan. Journal of Food, Agriculture and Environment 7(3-4):920-924.

Adams RP (2007). Identification of essential oil components by gas chromatography/mass spectrometry ( $4^{\text {th }}$ Ed). Allured Publishing Carol Stream, Illinois, USA.

Ahmad AM, Khokhar I, Ahmad I, Kashmiri MA, Adnan A, Ahmad M (2006). Study of antimicrobial activity and composition by GC/MS spectroscopic analysis of the essential oil of Thymus serpyllum. Internet Journal of Food Safety 5:56-60.
Alekseeva LI, Gruzdev IV (2012). Polymorphism of essential oils in Thyme species growing in European Part of North-East Russia and Ural. Russian Journal of Plant Physiology 59(6):818-827.

Amin G (2005). Popular medicinal plants of Iran. Tehran University of Medicinal Sciences Press, Tehran, Iran (In Persian).

Aziz S, Rehman H (2008). Studies on the chemical constituents of Thymus serpyllum. Turkish Journal of Chemistry 32:605-614.

Broucke CO, Lemli JA (1983). Spasmolytic activity of the flavonoids from Thymus vulgaris. Pharmacy World Science 5(1):9-14.

Chauhan NK, Singh S, Lohani H, Haider SZ (2011). Effect of different harvesting time on growth, yield and quality of Thyme (Thymus serpullym L.) under the agro-climatic conditions of Doon valley, Uttarakhand. Journal of Chemical and Pharmaceutical Research 3(6):982-986.

Davidson PM (1993). Parabens and phenolic compounds. In:Davidson PM, Branen AL (Eds). Antimicrobials in foods, $2^{\text {nd }} \mathrm{ed}$. Marcel Dekker Inc New York pp 263-305.

De Lisi A, Tedone L, Montesano V, Sarli G, Negro D (2011). Chemical characterization of Thymus populations belonging from Southern Italy. Food Chemistry 125:1284-1286.

Dorman HJ, Deans SG (2000). Antimicrobial agents from plants: antibacterial activity of plant volatile oils. Journal of Applied Microbiology 88:308-316.

European Pharmacopoeia 7.0 (2010). 1267-1268 p.

Eweis A, Imhemmed AA-A, Gad SA (2012). Influence of Thymus serpyllum essential oil on Aspergillus parasiticus morphology and aflatoxins production. Research Journal of Pharmaceutical, Biological and Chemical Sciences 3(2):322-332.

Farag RS, Daw ZY, Hewedi FM, El-Baroty GSA (1989). Antimicrobial activity of some Egyptian spice essential oils. Journal of Food Protection 52:665-667.

Farrukh R, Zargar MA, Akhtar A, Tasduq SA, Surjeet S, Nissar UA, Rakhshanda S, Masood A, Ganie SA, Shajrul A (2012). Antibacterial and antifungal activity of Thymus serpyllum. Botany Research International 5(2):36-39.

Guseinov SY, Kagramanova KM, Kasumov FY, Akundov RA (1987). Studies on the chemical composition and on some aspects of the pharmacological action of the essential oil of Thymus kotschyanus Boiss. Farmakologiya i Toksikologiya 50:73-74.

Hammer KA, Carson CF, Riley TV (1999). Antimicrobial activity of essential oils and other plant extracts. Journal of Applied Microbiology 86(6):985-990.

Ismaili $\mathrm{H}$, Sosa S, Brkic D, Fkih-Tetouani S, Ilidrissi A, Touati D, Aquino RP, Tubaro A (2002). Topical anti-inflammatory activity of extracts and compounds from Thymus Broussonettii. Journal of Pharmacy and Pharmacology 5(8):1137-1140.

Jaric S, Mitrovic M, Pavlovic P (2015). Review of ethnobotanical, phytochemical, and pharmacological study of Thymus serpyllum $\mathrm{L}$. Evidence-Based Complementary and Alternative Medicine doi:10.1155/2015/101978.

Jirovetz L, Wicek K, Buchbauer G, Gochev V, Girova T, Stoyanova A, Schmidt E (2007). Antifungal activity of various Lamiaceae essential oils rich in thymol and Carvacrol against clinical isolates of 
438

pathogenic Candida species. International Journal of Essential Oil Therapeutics 1:153-157.

Jukic M, Milos M (2005). Catalytic oxidation and antioxidant properties of thyme essential oils (Thymus Vulgarae L.). Croatica Chemica Acta 78(1):105-110.

Lambert RJW, Skandamis PN, Coote PJ, Nychas G-JE (2001). A study of the minimum inhibitory concentration and mode of action of oregano essential oil, thymol and carvacrol. Journal of Applied Microbiology 91:453-462.

Levic J, Cabarkapa I, Todorovic G, Pavkov S, Sredanovic S, CoghillGalonja T, Kostadinovic L (2011). In vitro antibacterial activity of essential oils from plant family Lamiaceae. Romanian Biotechnological Letters 16(2):6034-6041.

Loziene K, Venskutonis PR (2006). Chemical composition of the essential oil of Thymus serpyllum L. ssp. serpyllum growing wild in Lithuania. Journal of Essential Oil Research 18:206-211.

Maksimovic Z, Stojanovic D, Sostaric I, Dajic Z, Ristic M (2008). Composition and radical-scavenging activity of Thymus glabrescens Willd. (Lamiaceae) essential oil. Journal of the Science of Food and Agriculture 88(11):2036-2041.

Morales R (2002). The history, botany and taxonomy of the genus Thymus. In: Stahl-Biskup E, Saez F (Eds). Thyme the genus Thymus. Taylor \& Francis, London and New York pp 1-43.

Nabavi SM, Marchese A, Izadi M, Curti V, Daglia M, Nabavi SF (2015). Plants belonging to the genus Thymus as antibacterial agents: from farm to pharmacy. Food Chemistry 173:339-347.

Nikolic M, Glamoclija J, Ferreira ICFR, Calhelha RC, Fernandes A, Markovic T, Markovic D, Giweli A, Sokovic M (2014). Chemical composition, antimicrobial, antioxidant and antitumor activity of Thymus serpyllum L., Thymus algeriensis Boiss. and Reut and Thymus vulgaris L. essential oils. Industrial Crops and Products 52:183-190.

Osińska E, Węglarz Z, Angielczyk M (2002). Preliminary investigation on the variability of Thymus serpyllum $\mathrm{L}$. growing wild in Central Poland. In: Święcicki B, Naganowska B, Wolko B (Eds). Broad Variation and Precise Characterization-Limitation for the Future. Institute of Plant Genetics, Polish Academy of Sciences pp 253-256.

Oszagyan M, Simandi B, Sawinsky J, Kery A (1996). A comparison between the oil and supercritical carbon dioxide extract of Hungarian wild thyme (Thymus serpyllum L.). Journal of Essential Oil Research 8:333-335.

Pióro-Jabrucka E, Osińska E (2003). Comparative study on the variability of Thymus serpyllum L. in Poland. Annals of Warsaw Agricultural University, Horticulture (Landscape Architecture) 24:27-34.

Raal A, Paaver U, Arak E, Orav A (2004). Content and composition of the essential oil of Thymus serpyllum L. growing wild in Estonia. Medicina (Kaunas) 40(8):795-800.

Rasooli I, Mirmostafa SA (2002). Antibacterial properties of Thymus pubescens and T. serpyllum essential oils. Fitoterapia 73:244-250.
Santoyo S, Cavero S, Jaime L, Ibanez E, Senorans FJ, Regler G (2006). Supercritical carbon dioxide extraction of compounds with antimicrobial activity from Origanum vulgare L. determination of optimal extraction parameters. Journal of Food Protection 69(2):369-375.

Shelef LA (1983). Antimicrobial effects of spices. Journal of Food Safety 6:29-44.

Sikkema J, de Bont JAM, Poolman B (1995). Mechanisms of membrane toxicity of hydrocarbons. Microbiological Reviews 59(2):201-222.

Sokolic-Mihalak D, Frece J, Slavica A, Delas F, Pavlovic H, Markov K (2012). The effect of wild thyme (Thymus serpyllum L.) essential oil components against ochratoxin-producting Aspergilli. Arhiv za Higijenu Rada i Toksikologiyu 63:457-462.

Sokovic M, Glamoclija J, Marin PD, Brkic D, van Griensven LJLD (2010). Antibacterial effects of the essential oils of commonly consumed medicinal herbs using in vitro model. Molecules 15:7532-7546.

Thakuri BC, Padalia RC, Mathela CS (2009). Comparison of the volatile constituents of Thymus serpyllum from the altitude of far Western Nepal and North India. Scientific World 7(7):92-93.

Topal U, Sasaki M, Goto M, Otles S (2008). Chemical compositions and antioxidant properties of essential oils from nine species of Turkish plants obtained by supercritical carbon dioxide extraction and steam distillation. International Journal of Food Sciences and Nutrition 59(7-8):619-634.

Varga E, Bardocz A, Belak A, Maraz A, Boros B, Felinger A, Boszormenyi A, Horvath G (2015). Antimicrobial activity and chemical composition of thyme essential oils and the polyphenolic content of different Thymus extracts. Farmacia 63(3):357-361.

Verma RS, Verma RK, Chauhan A, Yadav AK (2011). Seasonal variation in essential oil content and composition of Thyme, Thymus serpyllum L. cultivated in Uttarakhand Hills. Indian Journal of Pharmaceutical Sciences 73(1):233-235.

Wesołowska A, Jadczak D, Grzeszczuk M (2012). Influence of distillation time on the content and composition of essential oil isolated from wild thyme (Thymus serpyllum L.). Herba Polonica 58(4):40-50.

Wesołowska A, Grzeszczuk M, Jadczak D (2014). Comparison of chemical compositions of essential oils isolated by hydrodistillation from wild thyme (Thymus serpyllum L.) with use of Deryng and Clevenger apparatus. Herba Polonica 60(2):7-17.

Wiegand I, Hilpert K, Hancock REW (2008). Agar and broth dilution methods to determine the minimal inhibitory concentration (MIC) of antimicrobial substances. Nature Protocols 3(2):163-175.

Zargari A (1990). Medicinal plants. Tehran University Press, Tehran, Iran 4:28-42 (In Persian)

Zarzuelo A, Crespo E (2002). The medicinal and non-medicinal use of thymeIn: Stahl-Biskup E, Saez F (Eds). Thyme the genus Thymus. Taylor and Francis, London and New York pp 263-286. 